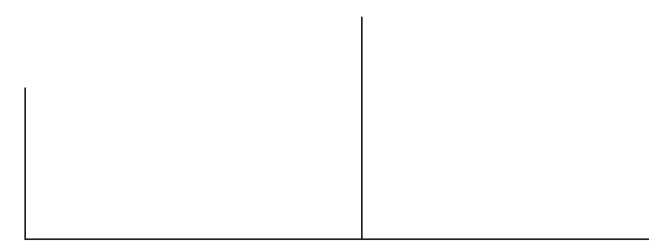

Rev. Latinoam. Psicopat. Fund., IV, 1, 86-93

\title{
O problema do diagnóstico em psicopatologia*
}

Gilda Paoliello

\begin{abstract}
A autora discute a questão do diagnóstico em psiquiatria, confrontando-o com o diagnóstico em medicina. Critica a tendência atual de se referenciar a psiquiatria no paradigma médico-científico, o que leva à exclusão do sujeito, do psiquiatra e da própria clínica.

Propõe o resgate da clínica em suas referências clássicas, aliada à ética do sujeito.

Palavras-chave: Psiquiatria, medicina, psicanálise, sujeito, objeto
\end{abstract}

* Texto apresentado no V Congresso Brasileiro de Psicopatologia Fundamental, 15 a 17 de setembro de 2000, Campinas, SP. 


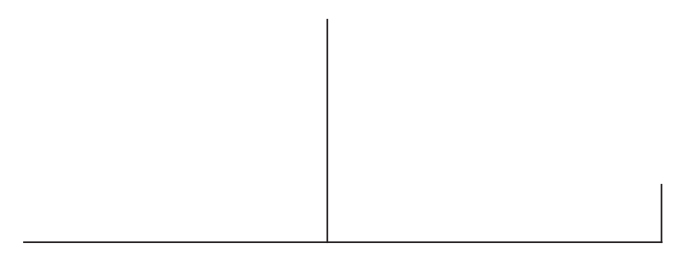

Estabelecer um diagnóstico em medicina não trás, na grande maioria dos casos, maiores problemas. O que é raro, é raríssimo, frase consagrada entre nossos colegas não psiquiatras. Há em medicina sinais funcionais, físicos, biológicos, objetivos, referidos ou não a uma etiologia conhecida, que permitem referenciar um doente numa categoria específica. A doença é uma diferença em relação a um estado que se define como saúde. Em psiquiatria é tudo muito diferente. Não há sinal objetivo algum, e a patologia mental, como regra, se inscreve em um distúrbio de comportamento em relação a uma norma. Mas qual o padrão de referência?

A psiquiatria atual teima em se referenciar em um modelo médico-científico, sem levar em conta se isso lhe cai bem ou não. E o faz de maneira desastrosa: deixa de lado o que a medicina tem de mais rico, que é a tradição clínica e a delicadeza do contato médico-paciente, com todas as suas particularidades, e vai buscar a neutralidade e o rigor nos avanços da ciência, como se fosse possível reduzir o seu objeto à doença. Nem a medicina se satisfaz com esse objeto e nem a medicina pode se refugiar em uma neutralidade, pois o médico, a todo instante, em sua prática se confronta com a necessidade de julgamento, seja no estabelecimento das condutas, seja na indicação de uma internação, na prescrição de uma medicação, na indicação de uma cirurgia ou até na indicação de uma alta: nem sempre podemos restringir esses atos médicos a modelos científicos tipo doença $\mathrm{X}$ conduta $\mathrm{Y}$.

$\mathrm{Na}$ busca da cientificidade a psiquiatria vai, cada vez mais, excluindo a subjetivação. O discurso da ciência desconsidera o sujeito e não se questiona sobre os efeitos do desejo, igno- 


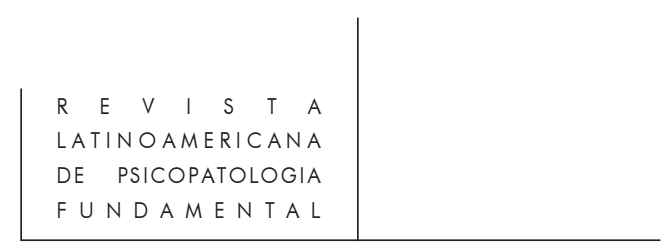

rando os efeitos provocados no pesquisador pelo objeto de sua pesquisa, em nome da tal neutralidade. É preciso lembrar que essa neutralidade é ilusória e que ela se baseia na exclusão da mediação exercida pelo próprio pesquisador e por seu quadro de referência na construção dos fenômenos observados. "A observação dos fenômenos clínicos não é jamais neutra nem tampouco as pesquisas sistematizadas dentro deste domínio" (Corin, 1989).

Essa preocupação com a objetividade se inscreve em um movimento amplo de objetivação e exteriorização da psiquiatria. Trata-se de um movimento veiculado pelas classificações americanas portadoras de um projeto da psiquiatria de reafirmar sua identidade médica e sua adesão à idéia de uma medicina científica (Corin, 1989).

Desde Hipócrates, a medicina tem procurado desenvolver uma prática baseada no modelo científico. Entretanto, pensadores como Khun, Rorty e Foucault nos convidam a criticar as reivindicações de que fatos médicos são verdades objetivas (Gillet, 1995).

Uma questão paradoxal ainda se coloca aqui: além de ceder seu espaço para campos alhures como as neurociências e a epidemiologia, em sua identificação com a medicina a psiquiatria vem cedendo na função de articular a complexidade dos fenômenos humanos, delegando esta função, na melhor das hipóteses, a outros campos da medicina que vêm considerando as interações somatopsíquicas na evolução das doenças somáticas. Em vez de se colocar em relação de extensão com a medicina, coloca-se assim em relação de extinção.

No mundo ocidental a evolução recente dos sistemas de pesquisa e a própria prática da psiquiatria estão sob o domínio do já citado modelo americano, o famigerado DSM-IV, sistema de classificação que impõe um valor exemplar e que manifesta a influência de um paradigma científico: a identidade médica da psiquiatria. Mas essa identidade, de acordo com esse sistema se resume numa enumeração de transtornos, dentro de uma perspectiva que se considera a-teórica e não etiológica, mas que não consegue disfarçar que se trata de uma clínica simplesmente de medicação, reduzindo a isso o modelo médico. Assim, bane o termo neurose, que nos remete a uma teoria, mas continua descrevendo os sintomas neuróticos. Ficam retidos somente os sintomas que são estatisticamente significativos para identificar um diagnóstico, que é feito considerando uma dimensão temporal dos distúrbios. Dessa forma, o diagnóstico de esquizofrenia não pode ser aplicado pela primeira vez antes dos 16 anos ou depois dos 45, e somente também pode ser dado se os distúrbios evoluem por pelo menos seis meses (Zefiran, 1986). Está psicótico, nessa classificação, aquele que alucina ou delira, ignorando-se completamente os riquíssimos fenômenos de linguagem que a psicanálise desvela. Nesse modelo, os métodos diagnósticos pretendem cada vez mais apreender o sintoma em sua exterioridade, a 


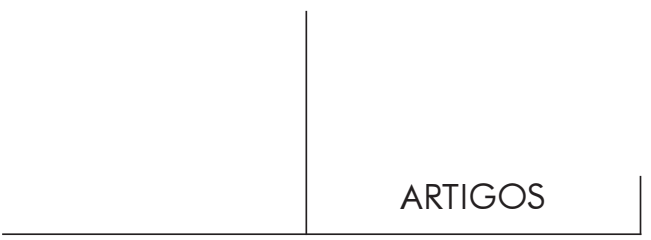

partir de grades e critérios que visam eliminar a subjetividade na avaliação dos sintomas e diagnóstico" (Corin, 1997).

O que esse sistema diagnóstico teria a nos dizer sobre um paciente que se nega a tomar Risperdal, porque isso tem a ver com Ribeirão, cidade onde seu pai foi assassinado e que, portanto, o coloca também em risco? E do paciente que nos pede para prescrever-lhe aquele remédio, mulheril, que o faria desejado pelas mulheres?

O psiquiatra não pode ignorar o fenômeno transferencial e se excluir do sintoma. Sabemos que essa posição não satisfaz; o sintoma psiquiátrico transcende o modelo médico. O psiquiatra não pode ficar preso à vertente sintoma/doença, devendo fazer com que o sujeito queira saber sobre a causalidade psíquica.

Reduzir a atividade psíquica à atividade cerebral é um ato ideológico. Não podemos confundir o telefone, seus fios e o sistema de condução dos impulsos com a mensagem transmitida. "Por mais que a ciência progrida, a psiquiatria jamais se reduzirá à medicina, a doença mental jamais se reduzirá à doença cerebral e o método anátomo-clínico jamais eliminará o modelo clínico. O problema não está no atraso da ciência, mas na natureza do objeto dos dois campos", conclui Francisco Paes Barreto, em $O$ nascimento da clínica.

Fala-se hoje em psiquiatria baseada em evidência. Muito bem, essas evidências têm sido bastante relativas e seus achados empíricos pouco relevantes: diferentemente das outras especialidades médicas a psiquiatria não dispõe de marcadores biológicos para a identificação de casos e a evidência científica tem-se resumido à resposta positiva ou negativa à medicação. Na maioria das vezes, o conhecimento de distúrbios da neurotransmissão tem servido não de base para o conhecimento do homem e seu sofrimento psíquico, mas servido principalmente para a síntese de novos produtos farmacêuticos de enorme eficiência terapêutica, sim, e que sem dúvida mudaram para melhor o tratamento de vários quadros psiquiátricos. Isso é uma verdade. O que fica difícil é aceitar a conclusão simplista de que a causa da depressão são as alterações da neurotransmissão como se isso explicasse a dor de existir. A causa verdadeira seria aquilo que promove as alterações da neurotransmissão, ou seja, estão afirmando que um distúrbio é a causa da depressão, sem saberem qual é a causa de tal distúrbio. Será que tristeza e sofrimento se devem também a alguma alteração química específica? Qual alteração química explicaria a ideação de negação num deprimido e a idéia de ruína em outro? Ou psicopatologicamente não tem importância se distinguir uma coisa e outra? O modelo da PGP como paradigma da doença psiquiátrica, preenchendo o ideal científico de correlacionar o quadro clínico com o substrato anatomopatológico não funcionou para os outros quadros, tendo sido abandonado desde o início do século passado (Kammerer, 1986). "Enquanto a medicina encontra sua verdade na anatomia patológica, a psiquiatria desaparece quando o paciente fecha os olhos e os lábios", assinala Barreto, no texto já citado, e 


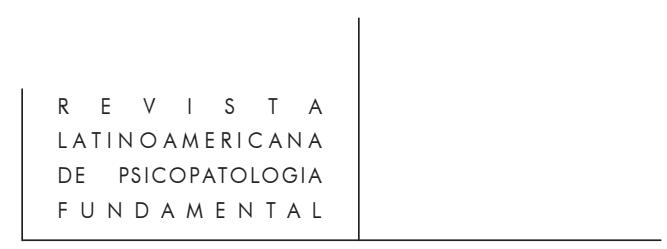

continua "os atuais métodos diagnósticos realizam uma dissecação virtual in vivo, estabelecendo uma relação direta entre o examinador e o substrato anatômico, dispensando uma mediação". Cria-se, assim, uma psiquiatria que se afasta dos princípios da clínica e se acerca do pan-opticon das neurociências, desconsiderando completamente o sujeito e suas particularidades. Nesse sentido, o rigor que a ciência empresta à psiquiatria é um rigor mortis, à medida que corresponde à morte do sujeito.

Podemos dizer mesmo que o rigor científico é mortal; a tendência atual da psiquiatria tem como resultado seu próprio suicídio, uma vez que:

1) Exclui o sujeito, o sujeito do ICS, o sujeito do desejo, para tratar o homem apenas como uma máquina neuronal, considerando o corpo apenas como um sistema homeostático, em sua pura presença animal, desconhecendo que ele é, sobretudo, um organismo desejante e gozoso (Barreto, 1999).

2) Exclui o próprio psiquiatra. Os instrumentos fundamentais do trabalho clínico, a entrevista e o exame mental já não são considerados seguros e valorizados. Os jovens psiquiatras, encantados com a tecnologia, já não se preocupam em dominar a arte e a técnica da entrevista. Kaplan e Saddock chegam a sugerir, em seu Tratado, que a entrevista seja feita por um psicólogo. O primeiro passo foi reduzir a função diagnóstica a uma classificação de transtornos, em que o psiquiatria teria como função identificar alguns fenômenos e inseri-los na classificação em vigor atualmente. Isso levado a um extremo já está acontecendo: na sala de espera onde o cliente preenche um formulário múltipla escolha, no qual ele vai identificar seus sintomas e queixas. Os dados são passados ao psiquiatra que, com referência no manual de classificação de doenças, faz o diagnóstico já dirigido para determinado tratamento medicamentoso. Daí a um computador fazer isso seria mais um pequeno passo que tornaria completamente dispensável a figura do psiquiatra.

3) Exclui a clínica: a substituição da figura do clínico pelo neurocientista, a exclusão da função de observação, deixando de se considerar a subjetividade e a transferência, correspondem ao desaparecimento da própria clínica.

Conclusão: a tendência atual da psiquiatria é excluir o paciente como sujeito, o psiquiatra e a clínica, implicando seu próprio extermínio.

Toda clínica é constituída do fato empírico, no caso o fato psíquico, e as categorias elaboradas para depreendê-lo. A clínica, seja ela médica, psiquiátrica ou psicanalítica, não consiste em uma simples aplicação do conhecimento científico. Nela a identificação de problemas e a tomada de decisões é totalmente dependente das referências utilizadas (Uchoa, 1999). Além disso, quando nos situamos no interior de um paradigma científico particular, ele nos parece impregnado de um caráter de evidência, reforçando a idéia de que por meio dele podemos apreender a realidade. Em se tratando do psiquismo, este pretendido acesso é ilusório, pois a realidade dos transtornos psíquicos nunca é objetiva. O caráter relativo desse paradigma só 


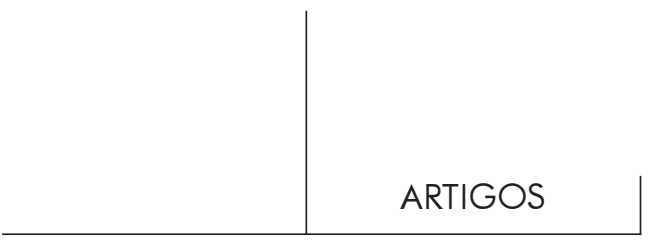

aparece quando nos situamos em suas margens ou limites e nos apoiamos em outras referências (Corin, 1997; Uchoa, 2000).

Então, não existe uma prática possível para a psiquiatria?

Longe disso. Acredito na psiquiatria e me vejo cada vez mais implicada na responsabilidade de resgatar a clínica. Imperativamente temos de contar com uma subjetivação sempre possível diante da qual a loucura é uma impossibilidade contingente (Garcia, 1999). A psiquiatria deve, então, em sua ação, estar voltada para os mecanismos singulares dessa impossibilidade. Ela deve ser, na tradição clínica, observação, diagnóstico e intervenção, lançando mão, nessa tarefa de um leque de recursos que sua extensão exige: recursos químicos, sociais/políticos e psicanalíticos, ao tentar diminuir a distância entre um animal humano e sua capacidade de subjetivação (Ibid.). O psiquiatra não pode considerar, a priori, alguém inapto à subjetivação. Ao contrário, o psiquiatra deve, a priori, apostar que há ali um sujeito e sustentar a possibilidade de que algo aconteça para fazer surgir este sujeito. A ética da psiquiatria deve avaliar o que pode um sujeito e o que desse poder ele é capaz de querer. Como disse Célio Garcia em nosso último Congresso Mineiro de Psiquiatria, sobre exatamente psiquiatria, ciência e ética, "necessário se faz não ceder, em nome da impotência da vontade, sobre a possibilidade do possível. O inimigo de uma prática ética seria a idéia do louco definitivo, do incurável a ser mantido sob a proteção de um sistema de saúde equipado para prever nos mínimos detalhes a neutralização dos efeitos da loucura", acrescento, inserindo-o em uma norma social que não lhe convém. É com esses parâmetros que a psiquiatria dita científica vem operando: poder normativo a serviço da adaptação social, como nos mostra de forma privilegiada o emprego das escalas de valores, as entrevistas estruturadas e os protocolos de conduta. O psiquiatra deve, portanto, ser capaz de denunciar tentativas de referência única a um grande Outro tirânico e unificador

Acredito, pratico e vejo resultados numa clínica capaz de articular as três linhas de orientação da psiquiatria: a biológica, a social e a psicanalítica.

É inegável a contribuição que as ciências vêm trazendo, principalmente em relação à psicofarmacologia, contribuição que se estende tanto para a psicanálise quanto para a reforma da assistência psiquiátrica. Não custa lembrar que a descoberta da clorpromazina nos anos 1950 foi o início da possibilidade de saída de pacientes dos hospitais. Hoje, o desenvolvimento dos novos antipsicóticos e o envolvimento das famílias nos tratamentos já nos permite manter o paciente inserido socialmente de forma mais segura e responsável.

É claro que os estudos atuais da genética, dos métodos propedêuticos, do conhecimento dos neurotransmissores e das novas descobertas da farmacologia têm trazido contribuições importantíssimas para o esclarecimento e tratamento de determinados quadros, aliviando o sofrimento e permitindo muitas vezes até que o paciente possa se sustentar numa análise, pois conhecemos bem os efeitos paralisantes de 


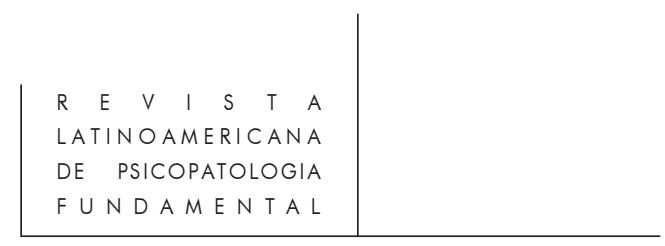

uma depressão. O que não podemos concordar é que o antidepressivo seja prescrito como se fosse um antibiótico e que o paciente seja desresponsabilizado de seus sintomas e de seu destino. Lembremos que Freud sempre apostou nos avanços da pesquisa médica até em relação a alguns casos neuróticos, como discute, por exemplo, em "O estado neurótico comum", porém nunca vacilou em acreditar que a função da psicanálise sempre estaria preservada em qualquer circunstância, ou seja, em sua proposta de investigar a função do inconsciente e suas conseqüências sobre a vida psíquica.

Nesse sentido, enquanto a psiquiatria empresta à psicanálise sua tradição clínica, suas categorias nosológicas e seus recursos farmacológicos a psicanálise empresta à psiquiatria sua ética: uma ética que aponta para o particular do desejo do sujeito, que privilegia a diferença, a singularidade, o caso a caso, ensinando a entrever nas malhas da estrutura clínica, o sujeito do inconsciente e sua transferência (Barreto, 1999).

É nesta psiquiatria que considera o homem como sujeito de desejo, de direito, sujeito da história e que este sujeito tem um corpo biológico do qual o inconsciente não se desvincula, uma psiquiatria que alia os avanços das neurociências às particularidades do sujeito e suas implicações sociais de cidadão, que acredito.

\section{Referências bibliográficas}

BARRETO, F. O nascimento da clínica. Jornal $O$ Risco, publicação da Associação Mineira de Psiquiatria, Ano XI, n. II, p. 8 e 9, Belo Horizonte, julho de 1999.

Corin, E.L. Les figures de l'étranger. P.R.I.S.M.E. (Psychiatrie, recherche et intervention en santé mentale de l'enfant), n. 8, pp. 196-206, 1998.

. Vers une ouverture sémiotique et culturelle du diagnostic psychiatrique. Colloque INSERME, v. 192, pp. 455-70, 1989.

Freud, S. (1916/17). O estado neurótico comum. In Conferências Introdutórias - parte III. E.S.B. Rio de Janeiro; Imago, 1976. v. XVI.

GARCIA, C. A humanidade se inventa a cada travessia do real. Jornal $O$ Risco, publicação da Associação Mineira de Psiquiatria, Ano XI, no 10, março de 2000, pp. 15-17.

GiLlet, G. Virtue and truth in clinical science. Journal of Medical Philosophy, Ano 20, n. 3, pp. 285-98, 1995.

Pereira, V. Experiência clínica e evidência científica. Texto apresentado no Pré-Congresso Brasileiro de Psiquiatria, organizado pela Associação Mineira de Psiquiatria, Belo Horizonte, 25/26 de agosto de 2000.

UсноA, E. Além das verdades absolutas. Jornal $O$ Risco, publicação da Associação Mineira de Psiquiatria, Belo Horizonte, Ano X, n. 8, agosto 1999.

. Evidência clínica e experiência científica - aspectos transculturais. Texto apresentado no Pré-Congresso Brasileiro de Psiquiatria, organizado pela Associação 


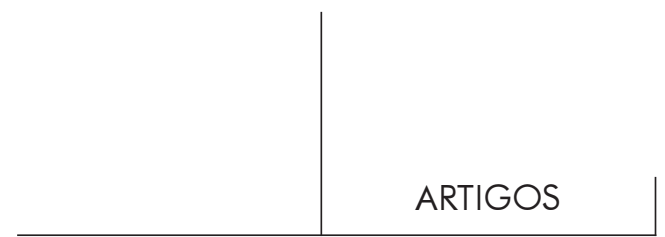

Brasileira de Psiquiatria, Belo Horizonte, 25/26 de agosto de 2000.

Zefiran, E. Um diagnóstico em psiquiatria - para quê? In A querela dos diagnósticos.

Rio de Janeiro: Jorge Zahar, 1986, pp. 45-51.

\section{Resumos}

La autora discute el tema del diagnostico en la psiquiatria y estabelece un analisis comparativo con el diagnostico en la medicina.

Critica la tendencia existente actualmente de referirse a la psiquiatria solamente dentro del paradigma medico cientifico, que lleva a la exclusion del sujeto, del psiquiatra y de la propia clinica.

Propone el resgate de la clinica desde el punto de vista clasico, aliada siempre a la etica del sujeto.

Palabras llave: Psiquiatria, psicoanalisis, sujeto, objeto

La question du diagnostic en psychiatrie est discutée en reférence au diagnostic en médicine. L'auteure critique la tendence actualle de la psychiatrie d s'appuyer sur le paradigme scientifique; cela amène a exclusion du sujet, du psychiatre et de la clinique même.

La proposition est de re-insérer la clinique dans les réferences classiques et dans une éthique du sujet.

Mots clés: Psychiatrie, psychanalyse, sujet, objet

The author discusses the question of diagnosis in psychiatry, comparing it with diagnosis in medicine. She criticizes the current tendency to refer to psychiatry according to the medical-scientific paradigm, which leads to the exclusion of the subject, the psychiatrist, and the clinic.

She proposes the return of the clinic, in its classical references, allied to the ethics of the subject.

Key words: Psychiatry, medicine, psychoanalysis, subject, object

Versão inicial recebida em novembro de 2000

Versão revisada recebida em fevereiro de 2001 